\title{
21 \\ Lessons for policy from Australia's experience with conservation tenders
}

\section{Graeme Doole and Louise Blackmore}

\section{Key lessons}

- This chapter reviews the drivers of cost-effectiveness in conservation tender programs, with a focus on what promotes landholder participation, based on survey results.

- Key lessons are drawn from the statistical analysis of survey responses from landholders, researchers, and agency staff with previous involvement in these schemes.

- Non-landholders identify the value of flexible tender designs, involving low-cost monitoring and strong relationships with stakeholders.

- Landholder responses suggest that tender schemes may have limited impact due to the crowding out of private investment, inadequate support during bidding and monitoring, and high administrative workload.

- Overall, future tender programs must employ options to counteract crowding out if they are to achieve additional environmental outcomes. 
Australia is one of 17 mega-diverse nations, which overall support more than 70 per cent of the world's biodiversity, but constitute less than 10 per cent of the global land area (Chapman 2009). The existing suite of protected areas found throughout Australia is inadequate to achieve broad biodiversity conservation, especially in regions highly favoured for agricultural production (Fitzsimmons and Wescott 2001). Over the past decade, there has been an increasing focus on conserving national biodiversity, broadly promoted in recent years through Australia's Biodiversity Conservation Strategy 2010-2030.

In particular, a strong motivation to achieve more cost-effective environmental outcomes on private land has stimulated the widescale use of market-based instruments (MBIs). Conservation tender (CT) schemes have been the most widely applied MBIs for biodiversity conservation throughout Australia to date. CT programs involve landholders submitting a bid to a management authority (e.g. regional natural management bodies or non-government organisations) outlining the actions they will take for a given payment. The authority evaluates the environmental benefit accruing to each set of actions and funds those landholder actions that will provide the greatest environmental benefit for the given budget (Latacz-Lohmann and Schilizzi 2005; Windle and Rolfe 2008).

The primary objective of this chapter is to review what drives the cost-effectiveness of CT programs, particularly relating to promoting the participation of landholders. Given the scarcity of available funds, it is justified that regulatory authorities seek to maximise the costeffectiveness of programs to motivate biodiversity conservation among Australian landholders (Pannell 2008). It is also consistent with the broad goal of Australia's Biodiversity Conservation Strategy 2010-2030 to deliver conservation initiatives in a cost-effective manner. A cost-effective or efficient program is defined as one that provides a given set of conservation outcomes at least cost. It is timely to reflect on the drivers of the cost-effectiveness of these programs, given that despite the broad employment of conservation auctions over the last decade throughout Australia, their use has now declined markedly. A number of potential reasons for this disadoption exist, including but not limited to thin markets, high administration costs for landholders and governing agencies, lack of political will to continue funding, and uncertainty for producers regarding the implications of their contracts. This study focuses on these drivers, 
among others, to explore what determines the cost-effectiveness of conservation auctions across Australia. This analysis is particularly timely, given that it reflects on past programs that arose during a period of proliferation for conservation auctions in Australia, using this information to guide how to gain the best return for public funds in future programs. These future programs are likely to be targeted, reinforcing the need for careful design. This summary provides a useful assessment of cost-effective design for auction programs, drawn from the Australian experience, for readers in other nations. Lessons here are drawn from the statistical analysis of survey responses from nonlandholders $(n=49)$ and landholders $(n=23)$ who have been involved in past CT programs. More detail regarding these studies are available in Doole et al. (2014) and Blackmore and Doole (2013) respectively. Non-landholders are researchers and agency staff who have previously been involved in CT schemes, while the landholders are previous CT participants from north central Victoria. Low sample sizes motivate the use of small-sample econometric methods (generalised maximum entropy regression) to analyse the primary drivers of cost-effectiveness and participation in the non-landholder and landholder data sets respectively (Golan et al. 1996).

\section{Results and discussion}

Statistical analysis of the results from the non-landholder survey (Doole et al. 2014) highlights five key lessons for improving the costeffectiveness of CT programs. Listed in decreasing order of importance, these are:

1. Increase funding for both individual tenders and groups of tenders. Respondents generally believed that the cost-effectiveness associated with tender implementation increased with their scale. This highlights the presence of increasing returns to scale, whereby the costs of tender implementation are believed to decline as tenders are more widely used, due to improved administrative efficiency and 'learning by doing' by the agency (Schilizzi and Latacz-Lohmann 2012). As experience and familiarity builds within agencies, it is thought that transaction costs will greatly decrease, allowing their cost-effectiveness advantages over flat rate subsidy schemes to be fully realised (Windle and Rolfe 2008). However, recent experience in Australia suggests that the development of this experience may 
be severely challenged, primarily by a lack of political will and the funding opportunities required for the continued implementation of these policy mechanisms. Broader adoption will also lead to more widespread achievement of biodiversity outcomes, provided these programs are effectively managed. Nevertheless, the overall scale of a program depends on the number of contracts formed and the scale of individual bids. A higher number of contracts will impose additional variable costs, such as those associated with monitoring. However, through learning from experience, cost-effectiveness associated with the fixed costs of a program, and some variable costs - for example, the development of more efficient monitoring programs - may fall across time.

2. Develop flexible tender designs for broad implementation. Substantial effort has now been invested in the assessment of tender programs involving different components - for example, through testing the relative implications of the number of rounds involved, whether tenders are budget- or target-constrained, whether bids are open or sealed, whether bidder information is symmetric or asymmetric, and so on (e.g. Schilizzi and Latacz-Lohmann 2007; Reeson et al. 2011; Boxall et al. 2012). However, the broad implementation of more generic tender designs may promote ease of organisation, and thereby the cost-effectiveness of these programs, as opposed to the development of auction designs that may suit a given set of circumstances more specifically, but are costly to identify and more difficult to apply. This principle has been observed in practice, with the success of the BushTender program (Stoneham et al. 2003) being replicated throughout Australia, in programs such as EcoTender and RiverTender. Nevertheless, it is important to note that such examples are very localised, with a high concentration in Victoria, and the number of examples across Australia is now in steady decline. The reasons for this decline are manifold, but mainly revolve around funding challenges and political climate. For these reasons, it is important to recognise that while the downscaling of auction programs will hamper learning by doing, the isolation of principles for cost-effective design identified throughout this chapter remain of key importance. Indeed, their significance is promoted when it is considered that a need for efficient delivery is even more pronounced when funds are scarce.

3. Encourage greater landholder competition. This result is consistent with strong theoretical (Latacz-Lohmann and van der Hamsvoort 1997) and empirical (Stoneham et al. 2003; Connor et al. 2008) 
evidence that this is a key principle underlying the success of CT programs, relative to subsidy schemes. Indeed, a central premise of neoclassical economics is that greater competition within markets will encourage greater efficiency through dissolution of market power. Nevertheless, a CT represents an artificial market, in which a management authority is the single buyer of products put forward by landholders. Accordingly, greater participation is not an end in itself. Indeed, there is an optimal number of participants that depends on balancing the impact of participation on competitive behaviour, while also considering its concomitant effect on evaluation, monitoring, and other administrative costs, especially those imposed prior to contract selection (Whitten et al. 2013).

4. Invest in means to identify low-cost monitoring strategies. Respondents highlighted the critical importance of addressing the difficulty associated with measuring the benefits of tenders for conservation activity and/or outcomes. Value for money in conservation programs depends on whether actions are achieving on-ground change (Connor et al. 2008). Accordingly, the development of appropriate low-cost management strategies is of vital importance. This result has also been identified for European MBI programs (Latacz-Lohmann and Schilizzi 2005).

5. Establish strong landholder relationships. New programs for environmental protection are difficult to understand for many landholders because of their complexity (Pannell et al. 2006). Accordingly, the overall cost-effectiveness of tenders was believed to respond to investment by regulatory authorities in landholder education and relationships. However, investment in relationships with landholders was determined to be around three times more important than investment in education and support in the non-landholder survey. This reflects the central importance of landholders as potential suppliers of improved environmental outcomes within tender programs. It also represents a critical challenge to auction programs, in that while these relationships are critical to success, they are also costly in terms of time and money. However, there is anecdotal evidence that these costs are mostly imposed in the early stages of a program, when familiarity and the competency of landholders is lower. Accordingly, these represent an explicit example of costs that decrease with learning by doing. 
Analysis of the results from the landholder survey using descriptive statistics (Blackmore and Doole 2013) highlights five key lessons for increased landholder participation within tender programs. Listed in decreasing order of importance, these are:

1. Crowding out of private conservation investment may be significant in Australian CT programs. Crowding out describes a situation where government funding drives down private funding, providing little or no additional benefit in terms of practical outcomes. In the context of conservation auctions, crowding out of private conservation investment infers that public funds provided for conservation expenditure through the tender mechanism merely offset private funding, providing little or no additional conservation benefit. There is only mild agreement among respondents that the time they had spent on conservation had increased during and after their participation in CT programs. Most respondents were conservation-minded, with 83 per cent of the sample stating that they were active members of at least two environmental groups. These results suggest that pre-existing levels of voluntary conservation effort among the sample were likely to be high. This is consistent with the findings of DSE (2006) and Moon et al. (2012), and suggests that crowding out may limit the cost-effectiveness of tenders throughout Australia. Efforts to engage landholders outside existing conservation communities may improve the conservation outcomes achieved by CT programs.

2. Landholders are likely to be receptive to 10-year contracts within tender programs. Shorter contracts (e.g. five years or less) often fail to achieve desired outcomes, whereas longer contracts (e.g. 15 years or more) represent a commitment beyond what landholders are willing to accept. This suggests a tension between landholders' desire to implement long-term conservation management strategies, and concerns relating to the limited tenure of farmers and the potential restriction of the options available to future generations farming that land.

3. Landholders feel that agency performance has been adequate in the areas of providing introductory materials and advertising, specifying management actions, and payment scheduling. These may be considered low-priority targets for future improvement.

4. Landholders feel agency performance needs improvement in the areas of providing information workshops, providing support during bid 
construction, and providing information regarding bid selection. Tender programs typically limit the quantity of information provided to participants to minimise the possibility of collusion, which involves landholders conspiring to submit inflated bids (Latacz-Lohmann and Schilizzi 2005). In this study, being unable to communicate with other participants, having limited support in constructing bids, and being confused about the bid-selection process left many landholders feeling isolated, frustrated, and even betrayed by the agency. There is evidence that landholder participants in the Environmental Stewardship Program have experienced similar issues (MJA 2010; Zammit 2013). Our results support those of Moon et al. (2012) and Whitten et al. (2007), indicating a need to ensure that landholders receive assistance and support to maintain or increase program participation, while seeking to minimise collusion among them.

5. Landholders feel that monitoring within tender programs requires improvement, with ongoing support during this phase an important step in better delivering management outcomes. Most landholders submitted annual reports to the agency, and monitoring site visits were generally infrequent or non-existent. A lack of monitoring visits made most landholders feel isolated and unsure of their ability to complete contracted tasks. Low monitoring activity by agency employees reflects cost concerns and a wish to promote ownership of the scheme by landholders. However, our results support those of Morrison et al. (2008), suggesting that more active, frequent monitoring by agencies could enhance participation rates, while also helping to improve the likelihood that meaningful environmental outcomes are attained among participants.

It is important to discuss the amount of information provided by regulatory authorities (see fourth point in the preceding list) further, since it has significant implications for auction performance. The distinction between information relating to the quality of alternative bids (in terms of their ability to deliver conservation outcomes) and that relating to price is critical. Information regarding the suitability of proposed actions put forward by participants is necessary for sensible bids, with both parties (sellers and buyers) within a conservation auction program benefiting from this data. 
In contrast, a lack of price information promotes competition among landholders; hence, management authorities responsible for the implementation of these schemes generally perceive it to be optimal to not provide such data. However, this action can reduce the probability that suitable practices are put forward for funding, while increasing the uncertainty faced by landholders regarding the construction of reasonable cost estimates. The latter can increase inefficiency above that experienced in subsidy programs, given that increasing bids will generally accompany greater uncertainty on the behalf of landholders (Latacz-Lohmann and van der Hamsvoort 1997).

The revelation of too much information can increase transactions costs and promote strategic bidding by landholders, which reduces competition and cost-effectiveness. Moreover, the provision of information workshops can strengthen landholder networks and potentially promote collusion. Survey results indicated that the agencies involved in implementing the programs that landholders had participated in generally provided less information, rather than more. Together with the inefficiency highlighted with a lack of information above, survey output suggests that these actions are actually hampering future participation in tender programs, given that one of the primary drivers of participation identified in the landholder survey is honest and respectful communication with the implementing agency (see below).

Analysis of the results from the landholder survey using small-sample econometric methods (Blackmore and Doole 2013) highlights five key lessons for increased landholder participation within tender programs. Listed in decreasing order of importance, these are:

1. Landholders are more likely to participate in future CT programs when they have a strong, respectful, and continuous relationship with the implementing agency, involving face-to-face contact. CT programs are more likely to succeed in areas characterised by strong, trusting agency-landholder relationships (Whitten et al. 2013). This is also thought to apply to the adoption of innovations more broadly (Pannell et al. 2006). Where such relationships are absent, personal engagement with landholders should be a high priority to ensure program success.

2. Landholders are more likely to participate in future $C T$ programs when the administrative load associated with participation is low. 
Streamlining the participation process is likely to enhance participation in future programs. This aspect is outlined in more detail in Chapter 16.

3. Landholders with an altruistic attitude and strong conservation focus, with a relatively low focus on monetary outcomes, are more likely to participate in future CT programs. Survey results indicate that 75 per cent of respondents would participate in future programs, but only 25 per cent of respondents believe that conservation tenders increase short-term income. These findings emphasise the significant potential for CT programs to crowd out voluntary conservation spending on Australian farms. Investigating strategies to engage landholders without these attributes will be critical to the achievement of broad-scale biodiversity outcomes. Accordingly, this has been a focus of the recent Environmental Stewardship Program (MJA 2010).

4. Landholders are less likely to participate in future CT programs when they have the necessary skills to undertake conservation works independently. The majority of respondents to the landholder survey highlighted that their primary driver to be involved in a CT program was not monetary, but rather altruistic and associated with a strong conservation ethic. Survey results indicate that landholders may become confident to manage an area for biodiversity conservation, independent of agency involvement, after their contracts expire. Ensuring that landholders leave programs with a high skill level and a realistic ongoing management plan could liberate funding to recruit new landholders into future CT schemes.

5. Landholders are less likely to participate in future CT programs if they have received strong support and education in previous schemes. Respondents generally had a strong conservation ethic and did not alter their conservation management efforts significantly during or after the CT program. Forty per cent of the sample found the cost of additional administrative work prohibitive. Accordingly, good support and education by the implementing agency was generally felt by participants to adequately equip them with the necessary skills to undertake future conservation projects, independent of agency involvement and the administrative burden associated with participation. 


\section{Conclusions}

Conservation tenders have been broadly utilised over the last decade for biodiversity conservation throughout Australia. It is timely to review what drives the cost-effectiveness of these programs, particularly relating to promoting the participation of landholders, to inform the future implementation of biodiversity markets.

Non-landholders generally believed that the cost-effectiveness of tender programs could be encouraged through the broad implementation of flexible tender designs that involved low-cost monitoring strategies and strong relationships with landholders. However, landholders highlighted that the cost-effectiveness of these schemes may be hampered due to the crowding out of private conservation investment, inadequate support during the bidding process and monitoring stage, and the workload associated with administration. Survey results showed that landholders within the sample are mainly driven by a strong conservation ethic and altruism, rather than a focus on monetary outcomes. Accordingly, many of the landholders who were interviewed changed their conservation activity little due to their involvement in a tender program. This highlights that the current use of tenders may actually achieve little additional benefit in terms of concrete biodiversity gains.

It is imperative to address the potential crowding out of public funding in CT schemes if they are to achieve prospective efficiency gains. Several means could be used to do so. First, market-segmentation analysis (Morrison et al. 2011) could be used to identify the characteristics of a given landholder population. This data can then be used to inform how a tender could be structured to reduce the potential for crowding out. Second, monitoring is important to ensure that trades are based on activity that is currently occurring. Third, encouraging landholders to submit the proportion of the total cost of an activity that they expect the agency to cover and the proportion they expect to cover encourages the idea that cost-sharing is expected, even if such information is not used during bid selection (Windle and Rolfe 2007). Last, a reserve price should be set, so that over-priced bids potentially inflated due to the substitution of private investment by agency funds - are not accepted. 


\section{Acknowledgements}

The authors would like to acknowledge funding and support received from National Environmental Research Program and the Centre of Excellence for Environmental Decisions.

\section{References}

Blackmore, L. and G.J. Doole (2013) `Drivers of landholder participation in tender programs for Australian biodiversity conservation', Environmental Science and Policy 33: 143-53.

Boxall, P.C., O. Perger and K. Packman (2012) 'An experimental examination of target-based conservation auctions', paper presented to the 56th Australian Agricultural and Resource Economics Society Conference, Fremantle.

Chapman, A.D. (2009) Numbers of living species in Australia and the World, Australia Biodiversity Information Services, Toowoomba.

Connor, J.D., J.R. Ward and B. Bryan (2008) 'Exploring the cost effectiveness of land conservation auctions and payment policies', Australian Journal of Agricultural and Resource Economics 52: 303-19.

Department of Sustainability and the Environment (DSE) (2006) BushTender - the landholder perspective, Department of Sustainability and Environment, Victoria.

Doole, G.J., L. Blackmore and S. Schilizzi (2014) 'Determinants of cost-effectiveness in tender and offset programs for Australian biodiversity conservation', Land Use Policy 36: 23-32.

Fitzsimmons, J. and G. Wescott (2001) 'The role and contribution of private land in Victoria to biodiversity conservation and the protected area system', Australian Journal of Environmental Management 8: 142-157.

Golan, A., G.G. Judge and D. Miller (1996) Maximum entropy econometrics: Robust estimation with limited data, Wiley, New York. 
Latacz-Lohmann, U. and C. van der Hamsvoort (1997) 'Auctioning conservation contracts: A theoretical analysis and an application', American Journal of Agricultural Economics 79: 407-18.

Latacz-Lohmann, U. and S. Schilizzi (2005) Auctions for conservation contracts: a review of the theoretical and empirical literature, SEERAD, Glasgow.

Marsden Jacob Associates (MJA) (2010) Review of the Environmental Stewardship Program, Marsden Jacob Associates, Melbourne.

Moon, K., N. Marshall and C. Cocklin(2012) 'Personal circumstances and social characteristics as determinants of landholder participation in biodiversity conservation programs', Journal of Environmental Management 113: 292-300.

Morrison, M., J. Durante, J. Greig and J. Ward (2008) Encouraging participation in market based instruments and incentive programs, Land and Water Australia, Canberra.

Morrison, M., J. Durante, J. Greig, J. Ward and E. Oczkowski (2011) 'Segmenting landholders for improving the targeting of natural resource management expenditures', Journal of Environmental Planning and Management 55: 17-37.

Pannell, D.J. (2008) 'Public benefits, private benefits, and policy intervention for land-use change for environmental benefits', Land Economics 84: 225-40.

Pannell, D.J., G.R. Marshall, N. Barr, et al. (2006) 'Understanding and promoting adoption of conservation practices by rural landholders', Australian Journal of Experimental Agriculture 46: 1407-24.

Reeson, A.F., L.C. Rodriguez, S.M. Whitten, et al. (2011) 'Adapting auctions for the provision of ecosystem services at the landscape scale', Ecological Economics 70: 1621-7.

Schilizzi, S., and U. Latacz-Lohmann (2007) 'Assessing the performance of conservation auctions: an experimental study', Land Economics 83: 497-515.

Schilizzi, S., and U. Latacz-Lohmann (2012) 'Conservation tenders: Linking theory and experiments for policy assessment', Australian Journal of Agricultural and Resource Economics 57: 1-23. 
Stoneham, G., V. Chaudhri, A. Ha and L. Strappazzon (2003) 'Auctions for conservation contracts: An empirical examination of Victoria's BushTender trial', Australian Journal of Agricultural and Resource Economics 47: 477-500.

Whitten, S.M., A. Reeson, J. Windle and J. Rolfe (2007) ‘Designing conservation tenders to support landholder participation: A framework and case study assessment', Ecosystem Services Journal 6: 82-92.

Whitten, S. M., A. Reeson, J. Windle, and J. Rolfe. (2013) 'Designing conservation tenders to support landholder participation: A framework and case study assessment', Ecosystem Services 6:82-92.

Windle, J. and J. Rolfe (2007) Competitive tenders for conservation contracts, Central Queensland University, Rockhampton.

Windle, J. and J. Rolfe (2008) 'Exploring the efficiencies of using competitive tenders over fixed price grants to protect biodiversity in Australian rangelands', Land Use Policy 25: 388-98.

Zammit, C. (2013) 'Landowners and conservation markets: Social benefits from two Australian government programs', Land Use Policy 31: 11-16. 
This text is taken from Learning from agri-environment schemes in Australia: Investing in biodiversity and other ecosystem services on farms, edited by Dean Ansell, Fiona Gibson and David Salt, published 2016 by ANU Press, The Australian National University, Canberra, Australia. 